\title{
PHOSPHORUS FORMS IN SOILS OF OBAN HILLS, AKAMKPA, CROSS RIVER STATE, NIGERIA
}

\author{
W. UBI, M. W. UBI, OTU IBOR AND A. U. AKPANIDIOK
}

(Received 19 June 2012; Revision Accepted 6 June 2014)

\begin{abstract}
Oban Hills is located at Akamkpa in the Southern Senatorial District of Cross River, State, Nigeria. Phosphorus (P)rich soil from the Hills is expected to have an effect on retention and distribution in the highly acidic soils surrounding the area inundated for several years. Phosphorus forms in the soils of the Hills varied with the year of deposition with the highest fraction being Ca-P. The low soil $\mathrm{pH}$ in the Oban Hills soils suggests that Ca-P may exist in a partially dissolved form and will be the primary source of $\mathrm{P}$ for vegetations around the area. The cation exchange capacity and $\mathrm{pH}$ of surface material from the Hills suggest a dominance of primary minerals. Based on the amount of $\mathrm{P}$ available it seems that the Hills soils play a role in the overall $P$ availability to the surrounding vegetation. A significant $(P<0.05)$ decrease in $\mathrm{HCl}$ soluble $\mathrm{P}$ with depth was observed in the $\mathrm{OB} 2$ soil site, where the greatest amount of $\mathrm{HCl}$-soluble $\mathrm{P}$ was found in the $0-15 \mathrm{~cm}$ soil depth. The bicarbonate $\mathrm{P}$ varied with sites $(\mathrm{OBI}, \mathrm{OB} 2$ and $\mathrm{OB} 3)$, and depth, but the OB3 had the highest value.
\end{abstract}

KEYWORDS: Phosphorus, Soils, Oban Hills, P-fixation, P-distribution

\section{INTRODUCTION}

Soils derived from Oban Hills have been a rich source of nutrients for many agricultural crops; however, the major limitations of the soils are phosphorus $(P)$ fixation, aluminum toxicity and high acidity (Holland et al, 1989). Due to the high $P$ fixation capacity of these soils, it is important to study the soil $\mathrm{P}$ transformation during soil development to assess temporal $P$ distribution and dynamics. Possible changes in soil $P$ forms in the course of pedogenesis have been predicted by some scientists (Lekwa and Whiteside 1986; Crews et al, 1995; Beck and Elsenbeer, 1999). Much work to investigate $\mathrm{P}$ forms present in soils of Oban Hills have not been done except the "Land Evaluation and Agricultural Recommendations" carried out by Holland et al (1989) for Cross River National Park, Oban Division. Phosphorus sequential fractionation methods have been considered as a useful tool in providing information regarding the link between biogeochemical cycle and forms of soil P. Although a relative increase in organic $P$ pools with increased weathering sequences has been observed, such a relationship has not been observed with labile soil $\mathrm{P}$ forms (Beck and Elsenbeer, 1999). In many Hills derived soils, fixation of $P$ by interaction with $\mathrm{Fe}$ and $\mathrm{Al}$ oxides has been a major factor governing $P$ availability to plants (Olander and Vitousek, 2005). It was proposed that $P$ fixation is mainly caused by the process of adsorption of $\mathrm{P}$ onto amorphous aluminum silicate clays by ligand exchange mechanism (Borie and Rubio, 2003). However, the rapid plant growth observed in certain tropical forest under limiting $P$ conditions has been ascribed to either lower $\mathrm{P}$ demand for forest vegetation compared to crops or effective competition for $\mathrm{P}$ (Olander and Vitousek, 2005). Soil $P$ fractionation methods extract operationally defined $P$ pools from various types of soils by sequentially removing them with different chemical reagents. This method has been used as a tool to identify predominant inorganic $\mathrm{P}$ pools in soils, which include water-soluble, Al-P, Fe-P, occluded and Cabound $\mathrm{P}$ forms (Hedley et al, 1982; Maguire et al, 2000; Ubi et al, 2009). The $P$ fractionation method used in this study enabled us to identify variations in predominant inorganic $\mathrm{P}$ pools including soluble surface-adsorbed, as well as $\mathrm{P}$ bound to $\mathrm{Ca}$ and $\mathrm{Fe} / \mathrm{Al}$ in Oban Hills derived and resulting soils, which allowed us to determine $\mathrm{P}$ availability to the vegetation.

The objectives of this study were:

(i) To investigate the $\mathrm{P}$ distribution in soils heavily inundated with $\mathrm{P}$ - rich Oban Hills derived materials, for prolonged time compared with the $P$ distribution in soils from areas down the crest. To investigate the $P$ forms in these soils and determine $P$ availability to plants.

\section{MATERIALS AND METHODS}

Description of Oban Hills

Oban Hills lies in Southeastern part of Akamkpa Local Government Area of Cross River State, Nigeria. The areas is located between latitudes $05^{\circ} 32^{1}$ and $04^{\circ} 27$ North and longitudes $07^{\circ} 15$ and $09^{\circ} 28^{\prime}$ East (Figure 1).

W. Ubi, Department of Science and Technology, National Open University, Calabar Study Centre Parliamentary, Calabar, Cross River State, Nigeria.

M. W. Ubi, Department of Soil Science, University of Calabar, Calabar, Cross River State, Nigeria.

Otu Ibor, Department of Forestry, University of Calabar, Calabar, Cross River State, Nigeria.

A. U. Akpanidiok, Department of Soil Science, University of Calabar, Calabar, Cross River State, Nigeria. 
The mean annual temperature is between 22.3 and $30^{\circ} \mathrm{C}$. The soil is basement complex, with rainfall of $2000 \mathrm{~mm}$ and mean relative humidity of $80-90$.

\section{Soil sampling}

(a) Soil samples were collected from the soil deposits on top of the Hills. Surface soils inundated were sampled from three sites, the top, middle and down the Hills in July 2010. These sites include:

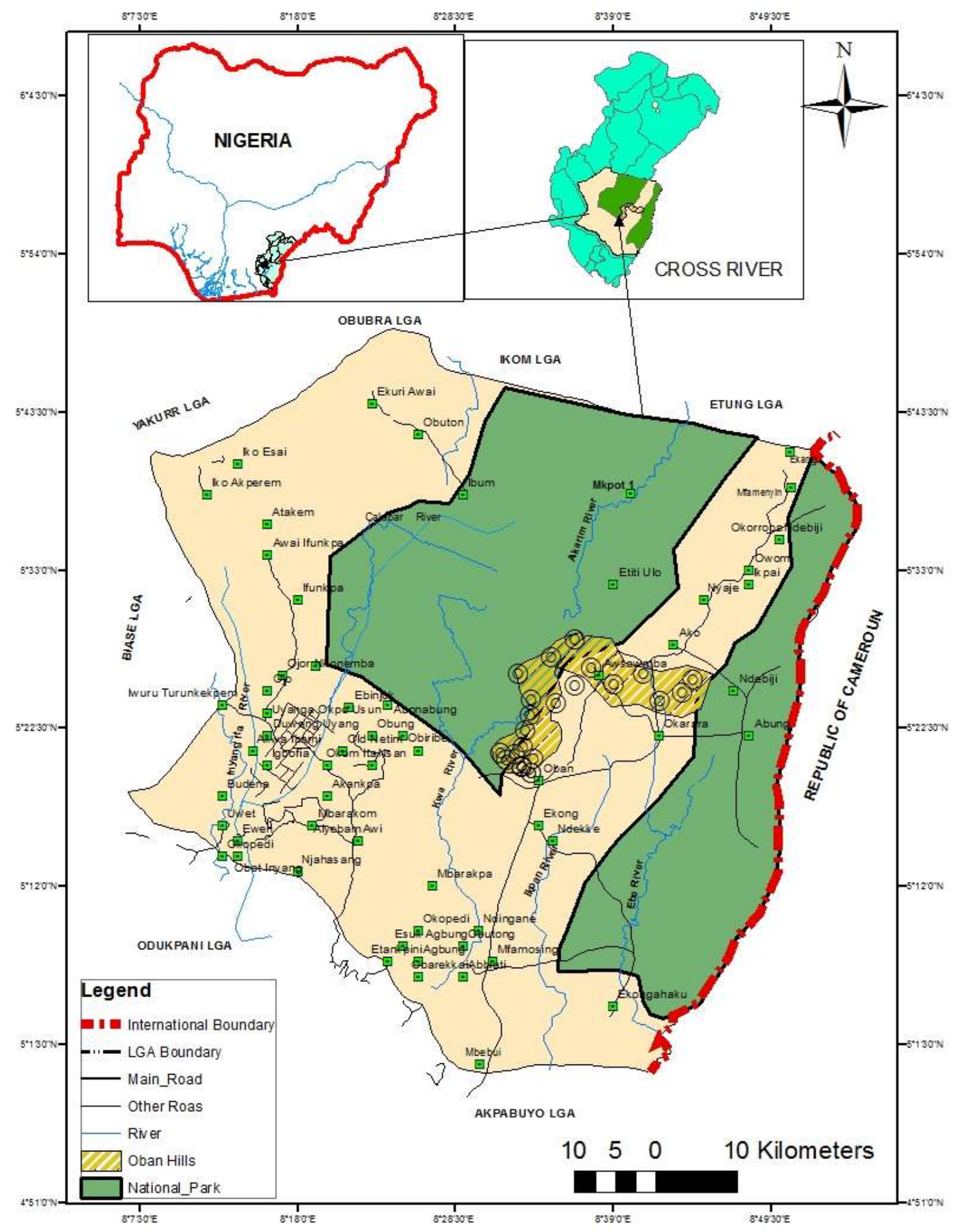

Figure 1: Map of Akamkpa Local Government Area showing Oban Hills 
(i) An area at the crest of the Hills (soils OBI), made up of basically shrubs and Mugambi spp.

(ii) The middle portion of the Hills (Soils OB2) vegetated by thick growth of guinea grass (Panicum maxima) and several other grass species, and

(iii) An area down the Hill (Soil OB3), supporting growth of oil palm (Felease indica) and shrubs. Soils were sampled at different depths from these sites. Soil cores taken from three sampling depth were composite and thoroughly mixed to prepare a composite sample for each depth. The soils were sampled at depths of $0-15,15$ to 30 and 30 to $45 \mathrm{~cm}$; for OB3. Soils in sites OBI and OB2 were difficult to sample due to frequent contact with boulders.

(b) Soil samples at each depth were composed of three composited samples collected from three locations per site fitted into $50 \times 50 \mathrm{~m}$ Latin square design.

(c) All soils were air dried and sieved via a 2-mm sieve. All analyses were carried out in triplicate.

\section{Chemical analyses}

Soil $\mathrm{pH}$ was measured in a soil in water (1:2) suspension using an Orion Model $410 \mathrm{pH}$ meter. Cation Exchange Capacity (CEC) was measured by the Bach extraction method (Hendershot and Duquete, 1986). Exchangeable $\mathrm{Al}$ was extracted with $1 \mathrm{M} \mathrm{KCl}$ solution and analyzed using an inductively coupled plasma optical emission spectroscopy (Bertsch and Bloom, (1996). Free $\mathrm{Fe}$ and Al oxides were measured by a previously described extraction method (Carter and
Gregerich, 2007). Phosphorus fractionation was carried out using the Hedley fractionation method (Hedley et ai, 1982 ) with a modification involving water extraction step to obtain water soluble $P$ in the soil. Soil $(\mathrm{O} .5 \mathrm{~g})$ was extracted sequentially with $30 \mathrm{ml}$ of water, $0.5 \mathrm{~m}$ $\mathrm{NaHCO}_{3}, \mathrm{O} . \mathrm{IM} \mathrm{NaOH}$, and $1 \mathrm{M} \mathrm{HCl}$ for $6 \mathrm{~h}$ with end-toend shaking. The use of other extractants for $P$ from Oban soil did not give meaningful results but with the use of $0.5 \mathrm{~m} \mathrm{NaHCO}$, which is not meant for acid soil (the result was satisfactory, which ordinarily should not be), probably due to non use of the soil for agricultural purposes since inception, and this calls for more research on this area.

\section{Statistical analysis}

Data were analyzed using GLM procedures of the statistical analysis system version 9.1. At each site, $P$ fractions were analyzed separately and compared depth wise. Sites were then compared by their values for SD and LSD for concentration of different $P$ forms at each depth. Treatment means were compared using little and Hills method of the DMRT procedure at $\mathrm{cl} 0.05$ within these sets of an analysis (SAS Institute, 1989).

\section{RESULTS AND DISCUSSION}

The $\mathrm{pH}$ of the soils ranged between 4.6 and 5.6 with a mean of 5.1 in 2010 and between 4.8 and 5.8 with a mean of 5.2 in 2011 (Table 1). The value for the two years tended to be similar, but the $\mathrm{pH}$ of the soils at the Hills bottom tended to be lower than that of soils supporting vegetation around it. The $\mathrm{pH}$ of the soil at the bottom was significantly $(P \leq 0.05)$ lower than the top and middle portion of the Hill for the two years.

Table 1: pH of soils at the top, middle and bottom of the Hills in 2010 and 2011

\begin{tabular}{|l|l|l|l|}
\hline & 2010 & 2011 & Mean \\
\hline Location of Hills & 5.6 & 5.8 & 5.7 \\
\hline Middle of Hills & 5.1 & 5.3 & 5.2 \\
\hline Bottom of Hills & 4.6 & 4.8 & 4.7 \\
\hline Mean & 5.1 & 5.2 & - \\
\hline SD & 0.72 & 0.73 & - \\
\hline CV & 11.60 & 11.86 & - \\
\hline LSD $(0.5)$ & 0.40 & 0.42 & - \\
\hline
\end{tabular}

The percentage distribution of $P$ forms in the top, middle and bottom of Hills is given in Table 2 .
Generally, there was a significant $(P \leq 0.05)$ in the different forms of $P$ as one moves from the top to the 
bottom of the Hill. The inorganic $P$ fractions in the soil deposits at different stages from top to bottom showed that 31.3 to $56.2 \%$ of $\mathrm{P}$ in the soil consisted of $\mathrm{HCl}-$ extractable $P$, indicating that most of these samples existed as Ca-bound forms. The amount of $\mathrm{HCl}-$ extractable $P$ being found in the soil varied with location on the Hills with the highest percentage being found in soils at the top of the Hills. However, a very low percentage of $\mathrm{Fe}$ and $\mathrm{Al}$ bound $\mathrm{P}$ was observed in the soil deposited at the bottom of the Hills.

$A$ very low percentage of water-soluble $P$ or $\mathrm{NaHCO}_{3}$ - extractable $\mathrm{P}$ form was detected from the top decreasing down the bottom, indicating low abundance of water-soluble or labile $\mathrm{P}$ forms from top to bottom.

\section{Inorganic $\mathbf{P}$ forms in Oban Hills soils}

The soil from the top of the Hills was basically humus in surface soils obtained from depths up to $30 \mathrm{~cm}$. The implication is that the surface soil was more acidic than deeper soil layers.

The CEC of the soil varied from 3.2 to $5.1 \mathrm{cmol}$ $\mathrm{kg}^{-1}$ (Table 3). The deeper soil layer $(45 \mathrm{~cm})$ had significantly higher CEC values than soils of the $0-30 \mathrm{~cm}$ depth. The CEC data in this study suggest that the surface soil consists of more primary than secondary clay minerals. Based on these results, it could be considered that there is a relationship between the increase in soil CEC and the amount of $P$ fixed in the Oban Hills derived soils, possibly caused by the reaction of $\mathrm{P}$ in the form of $\mathrm{H}_{2} \mathrm{PO}_{4}$ - (Mekaru and Vehara, 1972; Beck and Elsenbeer, 1999).

Table 2: Distribution of $\mathrm{P}$ forms (\%) in the Hill crest, middle and bottom of Oban Hill soils

\begin{tabular}{|l|l|l|l|l|l|}
\hline & $\begin{array}{l}\text { Water-P } \\
(\%)\end{array}$ & $\begin{array}{l}\mathrm{NaHC}_{03}-\mathrm{P} \\
(\%)\end{array}$ & $\begin{array}{l}\mathrm{NaH}-\mathrm{P} \\
(\%)\end{array}$ & $\begin{array}{l}\mathrm{HCl}-\mathrm{P} \\
(\%)\end{array}$ & $\begin{array}{l}\text { Residual P } \\
(\%)\end{array}$ \\
\hline OB1 (Top of Hills & 1.3 & 8.4 & 12.6 & 56.2 & 48.6 \\
\hline OB2 (Middle of Hills) & 1.1 & 6.5 & 10.7 & 48.9 & 35.4 \\
\hline OB3 (Bottom of Hills) & 0.8 & 4.4 & 8.5 & 31.3 & 24.1 \\
\hline Mean & 1.3 & 6.4 & 10.6 & 45.5 & 36.0 \\
\hline SD & 0.32 & 0.86 & 4.91 & 31.50 & 29.20 \\
\hline CV & 20.15 & 38.12 & 39.63 & 38.94 & 37.86 \\
\hline LSD (0.5) & 0.20 & 1.21 & 1.40 & 6.52 & 10.12 \\
\hline
\end{tabular}

$\mathrm{SD}=$ standard deviation; $\mathrm{CV}=$ coefficient of variation

Table 3: Variation of soil $\mathrm{pH}$ and $\mathrm{CEC}$ of soils from the top to bottom of Oban Hills

\begin{tabular}{|l|l|l|l|}
\hline Site & Depth $(\mathbf{C m})$ & $\mathbf{p H}$ & CEC 1 Cmolkg $^{-1}$ \\
\hline OB1 & $0-15$ & 4.4 & 3.7 \\
& $15-30$ & 4.2 & 3.4 \\
& $30-45$ & 5.6 & 5.1 \\
\hline OB2 & $0-15$ & 4.5 & 3.2 \\
& $15-30$ & 4.1 & 3.4 \\
& $30-45$ & 5.6 & 5.8 \\
\hline OB3 & $0-15$ & 4.7 & 3.5 \\
& $15-30$ & 4.5 & 4.8 \\
& $10-45$ & 5.4 & 6.4 \\
\hline
\end{tabular}


The distribution of $\mathrm{P}$ forms with depth is given in Figure 2. A significant variation in distribution of some $P$ can be observed in soils from different sites in the Hills. Very low amounts of water-soluble $P$, ranging from 2.1 to $6.9 \mathrm{mg} / \mathrm{kg}$ were present in the soils from the crest to the bottom. In site 3 (OB3) the deeper soil layers $(45 \mathrm{~cm})$ contained significantly $(P<0.05)$ more water soluble $P$, relative to other soil layers suggesting that there was $P$ transformation from one form to another and a downward movement of $\mathrm{P}$ in the soil profile forming part of $\mathrm{P}$ dynamics in the soil at certain $\mathrm{pH}$ levels. The bicarbonate $\mathrm{P}$ or labile $\mathrm{P}$ was in the range of 10.4 to 37.1 $\mathrm{mg} / \mathrm{kg}$ in the soil. The bicarbonate $P$ content varied with different sites (OB1, OB2, and OB3) and depths but the OB3 site had higher mean values of $P$. The highest $P$ pool found in these sites consisted of $\mathrm{HCl}$-soluble $\mathrm{OP}$, indicating that $P$ in the area was mainly composed of Ca-bound P. A significant $(\mathrm{P}<\mathrm{O} .05)$ decrease in $\mathrm{HCl}-$ soluble $\mathrm{P}$ with depth was observed in the OB2 soil area, where the greatest amount of HCL-extractable $\mathrm{P}$, was found in the $0-15 \mathrm{~cm}$ soil depth, which comprised about 58 of total inorganic $\mathrm{P}$ and the HCL extractable $\mathrm{P}$ at 45 $\mathrm{cm}$ soil depth comprised' only about 21 of total inorganic $\mathrm{P}$. The Na-P or Fe/Al- bound $\mathrm{P}$ pool was significantly $(\mathrm{P}<0.05)$ greater in site $2(\mathrm{OB} 2)$ relative to other sites up to the depth of 0 to $45 \mathrm{~cm}$ (Figure 2). The Fe/Albound $P$ in this site comprised on the average, about 58 of total inorganic $P$, whereas in the other sites only about 8.2 to 35 was identified as Fe/Al-bound P. Lowest amount of $\mathrm{Fe} / \mathrm{Al}$ bound $\mathrm{P}$ were found in site $\mathrm{I}(\mathrm{OBI})$ at all depths. Some significant variations were also found in Fe/Al-bound $P$ forms with depths in all sites. As it may be expected $\mathrm{Al}$ and $\mathrm{Fe}$ were the dominant soil components involved in $\mathrm{P}$ retention in acidic soils. Around $\mathrm{pH}<6, \mathrm{P}$ exist as $\mathrm{Al}-$ bound $\mathrm{P}$ and at lower $\mathrm{pH}, \mathrm{P}$ becomes fixed as Fe-P (Marguire et ai, 2000).

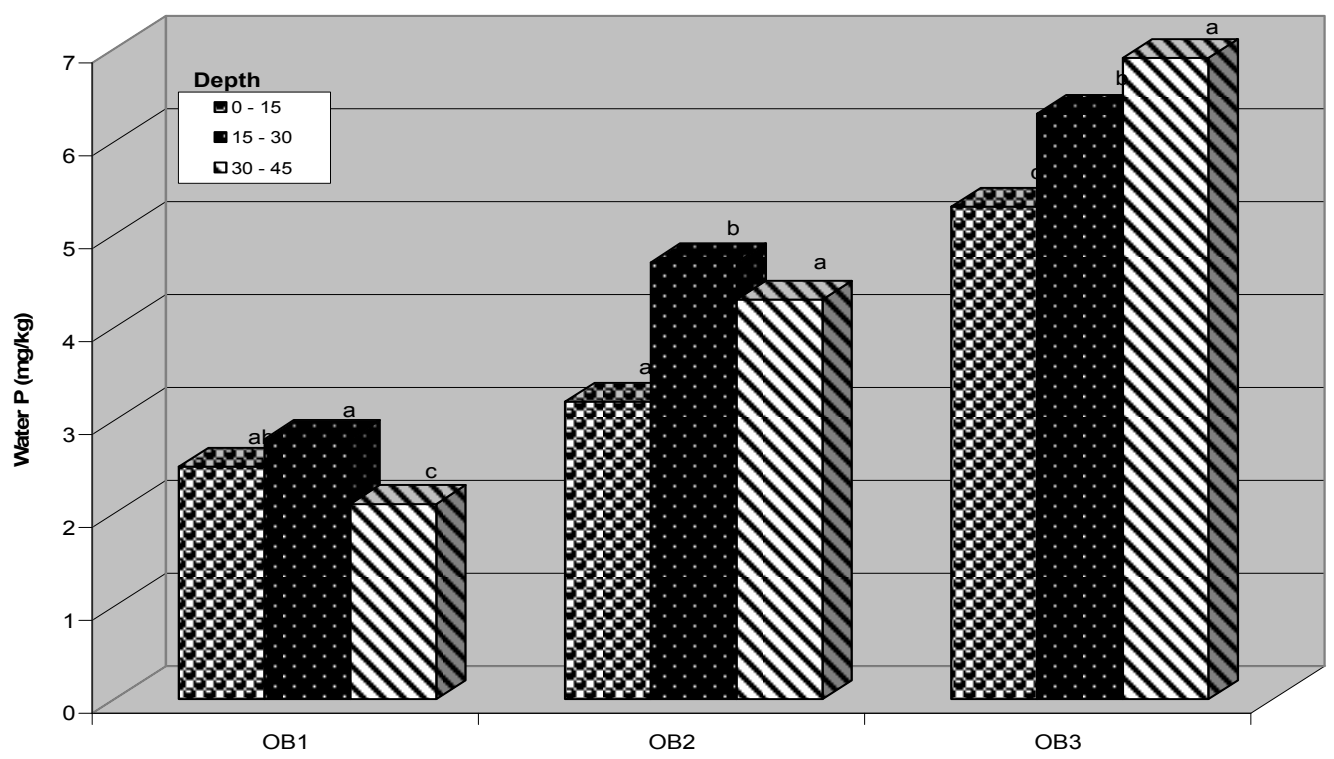

Figure 1a: Distribution of Water $P(\mathrm{mg} / \mathrm{kg})$ by depth in soils of Oban Hills from the crest to the bottom

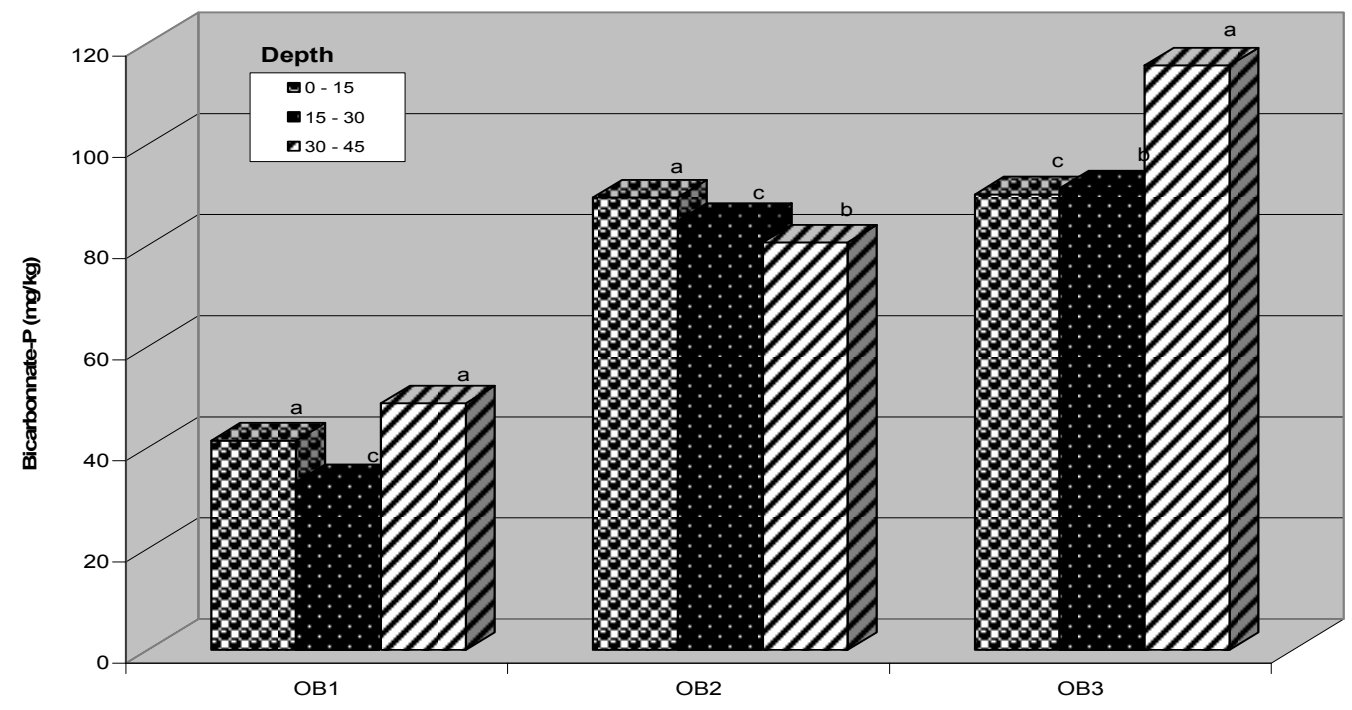




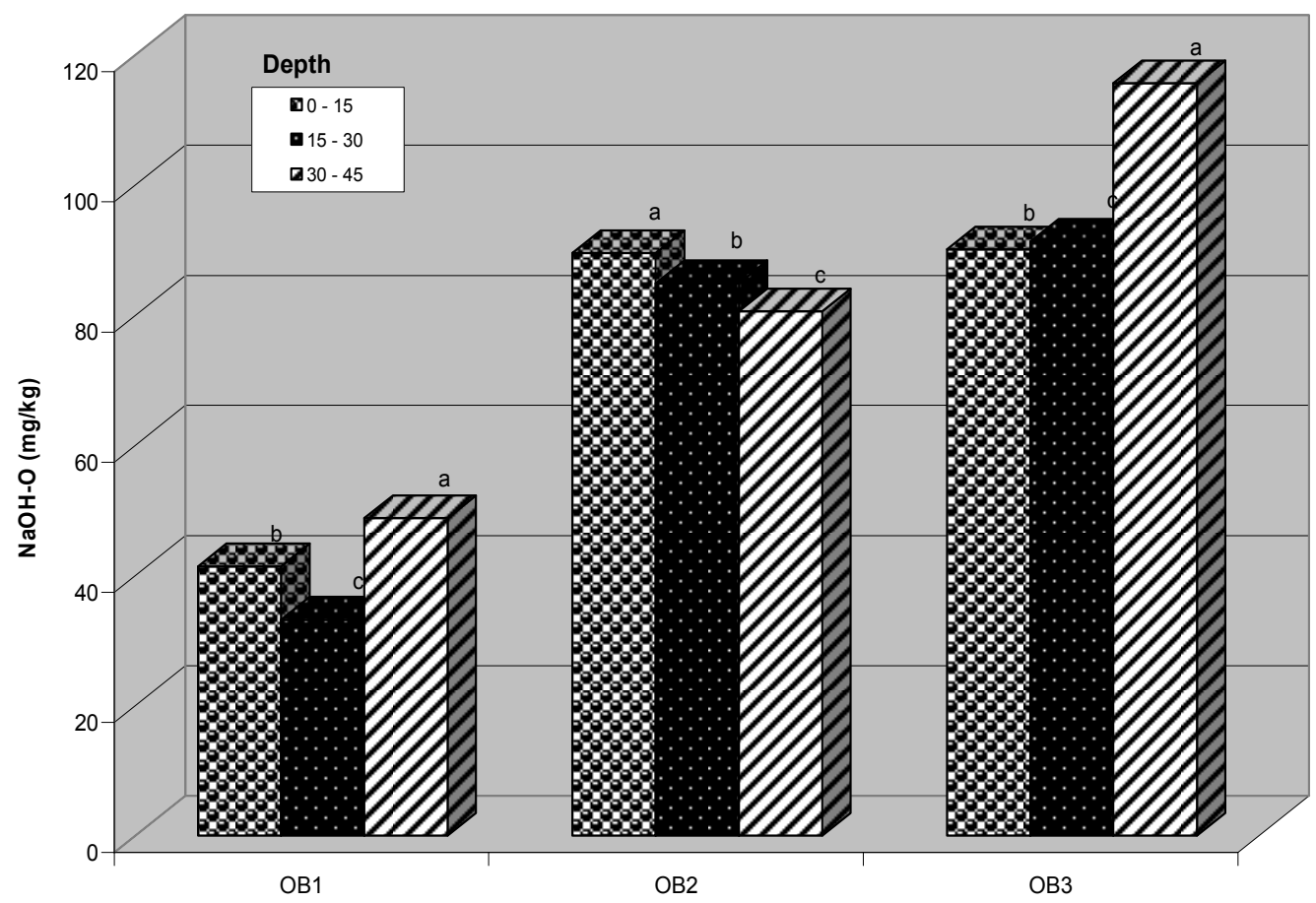

Figure 1c: Distribution of $\mathrm{NaOH}-\mathrm{O}(\mathrm{mg} / \mathrm{kg})$ by depth in soils of Oban Hills from the crest to the bottom

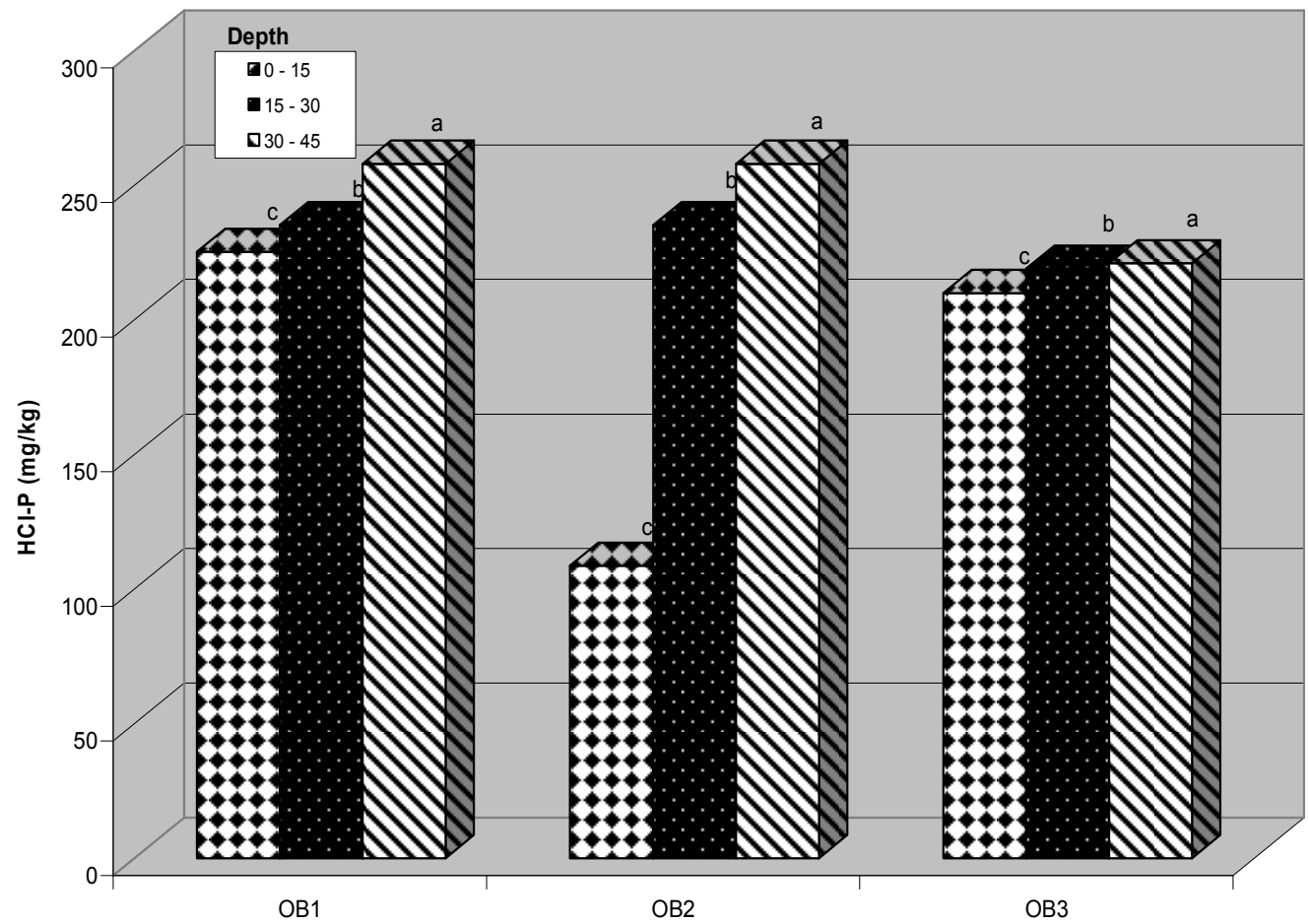

Figure 1d: Distribution of HCl-P (mg/kg) by depth in soils of Oban Hills from the crest to the bottom 
Earlier studies indicated that weathering of primary minerals accompanied by an increase in soil acidity leads to the formation of secondary minerals containing reactive $\mathrm{F}$, ! and $\mathrm{Al}$ oxides that provide a substrate for $\mathrm{P}$ sorption, thereby affecting the $\mathrm{P}$ availability to crops (Olander and Vitousek, 2005).

\section{CONCLUSION}

The $\mathrm{P}$ content in the Oban Hills soils was generally medium to high indicating that the $P$ will not be lacking if the soil is put into agricultural use. The study indicates that $\mathrm{P}$ availability was certainly restricted at all soil $\mathrm{pH}$ ranges observed due to lack of water soluble or labile $\mathrm{P}$. The low soil $\mathrm{pH}$ observed in these soils suggests that Ca-P may exist in a partially dissolved form and will be the primary source of $P$ for vegetation around the areas and crops grown around. The Oban Hills may not be deficient in $\mathrm{P}$. The amount of $\mathrm{HCL}$-extractable $\mathrm{P}$ being found in the soil varied with location on the Hills, with the highest percentage being found in soils at the top of the Hills. The Fe/Al bound $P$ pool was significantly $(P<0.05)$ greater in site $2(O B 2)$, relative to other sites up to the depth of $0-45 \mathrm{~cm}$, and contained more water soluble $P$.

\section{REFERENCES}

Beck, U. A and Elsenbeer, H., 1999. Biogeochemical cycles of soils phosphorus in southern Alpine Spodosols. Geoderma (91): 249-260.

Bone, F and Rubie, R., 2003. Total and organic phosphoric soils. Gayana Bot. (60): 69-78.

Betsch, P. M and Bloom, P. R., 1996. Aluminum In D.L. Sparks (ed) Methods of Soil Analys is. Part 3 Chemical Methods. Soil Sci. Soc. Am Book Series No.5 Agronomy 18: 5 17-543.

Crew, T. E., Kitayama, K., Fownes, J. H., Riley, R. H., Herbert, D. A., MuclierDombois, D and Vitousek, P. M., 1995. Changes in Soil Phosphorus fractions and ecosystem dynamics across a long chronosequence in Hawaii. Ecosystem dynamics across a long chronosequence in Hawaii. Ecology (76): 1407-1424.
Cater, M. R and Gregorich, E. G., (eds) 2007. Soil sampling and methods of analysis 2' Ed. CRS Press, Boca Raton FL.

Druitt, T. H and Kokelara, B. P., (eds) 2002. The Eruption of Soufriere Hills Volcano, Monstserrat from 1995-1999. geological society Memoir No.12 Geolog cal Society of London, London UK.

Eshett, E. T., 1985. Soil characteristics and farming systems in Northern Cross River State of Nigeria. P.hD Thesis, University of Ibadan, Nigeria .

Hedley, M. J., Stewart, J. W. B and Chautian, B. S.,

1982. Changes in inorganic and organic soil phosphorus fractions induced by cultivation practices and by laboratory incubation. Soil Sci. Soc. Am J. (46): 970-976.

Holland, M. D., Allen, D. B and Murphy, S. T., 1989. Cross River National Park Oban Division. Land Evaluation and Agriculture Recommendations. pp 140.

Lekwa, G and Whiteside, C. P., 1986. Coastal Plain Soils of South Eastern Nigeria. 11 Forms of Extractable Iron, Aluminum and phosphorus. Soil Sci. Soc. Of Am. J. (50): 160-166.

Maquire, R. 0., Sims, J. T and Coale, F. J., 2000. Phosphorus fractionation in Bio-solids amended soils. Relationship to soluble and desorbable phosphorus. Soil Sci. Soc. Am. J. (64): 20 182024.

Makaru, T and Uehara, G., 1972. Anion adsorption in ferruginous Tropical Soils. Soil Sci. Soc. Am. J. 3 6:296-300.

Olander, L. P and Vitousek, P. M., 2005. Short-term controls over inorganic phosphorus during soil and ecosystem development. Soil, Biol. Bichem. (37): 65 1-659

SAS Institute., 1989. SAS users Guide Statistics SAS Institute, Inc. Carry. North Carolina (NC). 